\title{
Gains from trade and efficiency under monopolistic competition: a variable elasticity case*
}

\author{
Kristian Behrens $^{\dagger} \quad$ Yasusada Murata ${ }^{\ddagger}$
}

February 28, 2006

\begin{abstract}
We present a general equilibrium model of monopolistic competition with variable demand elasticities and investigate the impact of free trade on welfare and efficiency. First, contrary to the constant elasticity case, in which all gains from trade are due to increasing product diversity, our model features gains from pro-competitive effects. Second, we show that the market outcome is not constrained efficient because too many firms operate at an inefficiently small scale. Last, we prove that free trade raises efficiency by narrowing the gap between the equilibrium utility and the constrained optimal utility.
\end{abstract}

Keywords: international trade; monopolistic competition; variable elasticity; gains from trade; efficiency

JEL Classification: D43; D51; F12

\footnotetext{
${ }^{*}$ We thank Takumi Naito, Gianmarco I.P. Ottaviano and Pierre M. Picard for valuable comments on an earlier draft of this paper. The first author gratefully acknowledges financial support from the European Commission under the Marie Curie Fellowship MEIF-CT-2005-024266. This research was partially supported by the Ministry of Education, Culture, Sports, Science and Technology (MEXT, Japan), Grant-in-Aid for 21st century COE Program. Part of the paper was written while both authors were visiting KIER, Kyoto University, and while the first author was visiting ARISH, Nihon University. We gratefully acknowledge the hospitality of these institutions. The ususal disclaimer applies.

${ }^{\dagger}$ CORE, Université catholique de Louvain, 34 voie du Roman Pays, 1348 Louvain-la-Neuve, Belgium. E-mail: behrens@core.ucl.ac.be

${ }^{\ddagger}$ Advanced Research Institute for the Sciences and Humanities, Nihon University, 12-5, Gobancho, Chiyoda-ku, Tokyo 102-8251, Japan. E-mail: murata@arish.nihon-u.ac.jp
} 


\section{Introduction}

Few trade theorists would disagree with the statement that product variety, scale economies, and pro-competitive effects are central to any discussion about gains from trade and efficiency with imperfect competition and differentiated goods. ${ }^{1}$ Yet, it is fair to say that, until now, these questions have not been fully explored within a simple and solvable general equilibrium model of monopolistic competition. This is largely due to the fact that the workhorse approach to international trade under monopolistic competition, namely the constant elasticity of substitution (henceforth, CES) framework, displays two peculiar features. First, it does not allow for procompetitive effects so that "there is no effect of trade on the scale of production, and the gains from trade come solely throught increased product diversity" (Krugman, 1980, p.953). Second, the equilibrium in the CES model is usually constrained optimal, i.e., the market provides the socially desirable number of varieties at an efficient scale (Dixit and Stiglitz, 1977). Consequently, trade is not efficiency enhancing because it does not correct the only market failure, pricing above marginal cost.

In order to fully explore gains from trade and efficiency under monopolistic competition, we must depart from the standard CES model in some respect. In the present paper, we propose a simple and tractable variable elasticity of substitution (henceforth, VES) model, despite the widely-held view that VES models have until now unfortunately "not proved tractable, and from Dixit and Norman (1980) and Krugman (1980) onwards, most writers have used the CES specification" (Neary, 2004, p.177). ${ }^{23}$ Building on previous work by Behrens and Murata (2005), we present a general equilibrium model of international trade that displays the following four features: (i) it has variable mark-ups and, therefore, accounts for pro-competitive effects; (ii) it has a competitive limit when the mass of firms becomes arbitrarily large; (iii) it exhibits gains from trade due to both product diversity and to pro-competitive effects; and (iv) it allows for a constrained efficiency analysis.

\footnotetext{
${ }^{1}$ Dixit (2004, p.128), e.g., summarizes the gains from trade under monopolistic competition as follows: (i) availability of greater variety; (ii) better exploitation of economies of scale; and (iii) greater degree of competition, driving prices closer to marginal costs.

${ }^{2}$ Interestingly, Lawrence and Spiller (1983, p.66) point out that the assumption that "the elasticity of demand is independent of the number of competitors is not intuitively appealing", and they suggest a specification in which the elasticity of demand depends on the number of varieties. They leave the analysis of its implications for future research, and to the best of our knowledge it has not been tackled until today.

${ }^{3}$ Another possibility that has been recently explored in the literature is the introduction of heterogeneous firms within the well-established CES framework (Melitz, 2003).
} 
Previewing our main results, we concisely illustrate the well-known fact that free trade leads to an increase in the mass of varieties consumed, and to a decrease in the mass of varieties produced in each country (Feenstra, 2003). We also show that exit under free trade is accompanied by an increase in output per firm, which leads to a better exploitation of firm-level scale economies. Although the per capita consumption of each variety decreases, gains from trade materialize because of product diversity and pro-competitive effects. We illustrate these points by welfare decomposition. Finally, we show that free trade increases efficiency by moving the market outcome closer to the constrained optimum. This effect is stronger when the trading partners are large, yet even free trade does not lead to an efficient outcome in our setting.

Before continuing, one word of caution is in order. Some of the results we present in this paper have been 'in the air' for a quite a while. Indeed, Dixit and Norman (1980), Krugman (1980, 1981), Lawrence and Spiller (1983), Helpman and Krugman (1985), Wong (1995), and Feenstra (2003), among others, analyze certain aspects of gains from trade with differentiated products under monopolistic competition. Yet, these gains have not been systematically explored in a simple and solvable general equilibrium model with VES, as we do in this paper. Our new specification therefore enriches models like Krugman's (1979) seminal paper, by making them more tractable and by allowing us to push further the investigation of additional aspects such as efficiency. This point, namely the formal analysis of the impact of free trade on efficiency under monopolistic competition has, to the best of our knowledge, not yet been provided in the literature.

The remainder of the paper is organized as follows. Section 2 develops the model, and Section 3 discusses the autarky case. Section 4 presents the free trade case, analyzes the trade equilibrium (Section 4.1), decomposes the gains from trade (Section 4.2) and shows that free trade moves the economy closer to the constrained optimum and is, therefore, efficiency enhancing (Section 4.3). Section 5 concludes and points towards future research directions.

\section{Model}

\subsection{Preferences}

Consider a world with two countries, labeled $r$ and $s$. Variables associated with each country will be subscripted accordingly. There is a mass $L_{r}$ of workers/consumers in country $r$, and each worker supplies inelastically one unit of labor. Thus, $L_{r}$ also stands for the total amount of labor available in country $r$. We assume that labor 
is internationally immobile and that it is the only factor of production.

There is a single monopolistically competitive industry producing a horizontally differentiated consumption good with a continuum of varieties. Let $\Omega_{r}$ (resp., $\Omega_{s}$ ) be the set of varieties produced in country $r$ (resp., $s$ ), of measure $n_{r}$ (resp., $n_{s}$ ). Hence, $n \equiv n_{r}+n_{s}$ stands for the (endogenously determined) mass of available varieties in the global economy. A representative consumer in country $r$ solves the following consumption problem:

$$
\begin{gathered}
\max _{q_{r r}(i), q_{s r}(j)} U_{r} \equiv \int_{\Omega_{r}}\left[1-\mathrm{e}^{-\alpha q_{r r}(i)}\right] \mathrm{d} i+\int_{\Omega_{s}}\left[1-\mathrm{e}^{-\alpha q_{s r}(j)}\right] \mathrm{d} j \\
\text { s.t. } \int_{\Omega_{r}} p_{r}(i) q_{r r}(i) \mathrm{d} i+\int_{\Omega_{s}} p_{s}(j) q_{s r}(j) \mathrm{d} j=E_{r},
\end{gathered}
$$

where $\alpha>0$ is a utility parameter; $E_{r}$ stands for the consumer's expenditure; $p_{r}(i)$ denotes the price of variety $i$, produced in country $r$; and $q_{s r}(j)$ stands for the per-capita consumption of variety $j$, produced in country $s$ and sold in country $r$.

We show in Appendix A that the demand functions for country- $r$ consumers are given as follows:

$$
q_{r r}(j)=\frac{E_{r}-\frac{1}{\alpha} \int_{\Omega_{r}} \ln \left(\frac{p_{r}(j)}{p_{r}(i)}\right) p_{r}(i) \mathrm{d} i-\frac{1}{\alpha} \int_{\Omega_{s}} \ln \left(\frac{p_{r}(j)}{p_{s}(i)}\right) p_{s}(i) \mathrm{d} i}{\int_{\Omega_{r}} p_{r}(i) \mathrm{d} i+\int_{\Omega_{s}} p_{s}(i) \mathrm{d} i},
$$

Mirror expressions hold for country- $s$ consumers. Because of the continuum assumption firms are negible, so that the own-price derivatives of the demand functions are given as follows:

$$
\frac{\partial q_{r r}(j)}{\partial p_{r}(j)}=-\frac{1}{\alpha p_{r}(j)} \quad \frac{\partial q_{s r}(j)}{\partial p_{s}(j)}=-\frac{1}{\alpha p_{s}(j)}
$$

Mirror expressions hold again for country $s$.

\subsection{Technology}

All firms have access to the same increasing returns to scale technology. To produce $Q(i)$ units of any variety requires $l(i)=c Q(i)+F$ units of labor, where $F$ is the fixed and $c$ is the marginal labor requirement. We assume that firms can costlessly 
differentiate their products and that there are no scope economies. Thus, there is a one-to-one correspondence between firms and varieties, so that the mass of varieties $n$ also stands for the mass of firms operating in the global economy. There is free entry and exit in each country, which implies that $n_{r}$ and $n_{s}$ are endogenously determined by the zero profit conditions. Consequently, the consumer's income $w_{r}$ equals the wage in country $r$.

International markets are assumed to be integrated, so that firm $i \in \Omega_{r}$ sets a unique free-on-board price $p_{r}(i)$ for consumers in both countries. Its profit is then as follows:

$$
\Pi_{r}(i)=\left[p_{r}(i)-c w_{r}\right] Q_{r}(i)-F w_{r}
$$

where $Q_{r}(i) \equiv L_{r} q_{r r}(i)+L_{s} q_{r s}(i)$ stands for its total output.

\subsection{Equilibrium}

Country-r (resp., country-s) firms maximize their profit (5) with respect to $p_{r}(i)$ (resp., $\left.p_{s}(j)\right)$, taking $\left(n_{r}, n_{s}, w_{r}, w_{s}\right)$ as given. ${ }^{4}$ This yields the following first-order conditions:

$$
\begin{aligned}
\frac{\partial \Pi_{r}(i)}{\partial p_{r}(i)} & =Q_{r}(i)+\left[p_{r}(i)-c w_{r}\right]\left[L_{r} \frac{\partial q_{r r}(i)}{\partial p_{r}(i)}+L_{s} \frac{\partial q_{r s}(i)}{\partial p_{r}(i)}\right]=0 \\
\frac{\partial \Pi_{s}(j)}{\partial p_{s}(j)} & =Q_{s}(j)+\left[p_{s}(j)-c w_{s}\right]\left[L_{s} \frac{\partial q_{s s}(j)}{\partial p_{s}(j)}+L_{r} \frac{\partial q_{s r}(j)}{\partial p_{s}(j)}\right]=0 .
\end{aligned}
$$

Conditions (6) and (7) highlight a fundamental property of monopolistic competition models: although each firm is negligible to the market (no 'direct strategic interactions' between firms), it must take into account the aggregate pricing decisions of the other firms since their prices enter the first-order conditions ('weak strategic interactions' via the price aggregates). Formally, our equilibrium concept is that of a Nash equilibrium with a continuum of players. ${ }^{5}$

In what follows, let $\left(\mathbf{p}_{r}^{*}, \mathbf{p}_{s}^{*}\right)$ stand for a price equilibrium, i.e., a distribution satisfying (6) and (7) for all $i \in \Omega_{r}$ and $j \in \Omega_{s}$. We will discuss its existence, uniqueness, and some other properties in the following sections.

An equilibrium is a price equilibrium and a vector $\left(n_{r}^{*}, n_{s}^{*}, w_{r}^{*}, w_{s}^{*}\right)$ of firm distribution and factor prices such that national factor markets clear, trade is balanced,

\footnotetext{
${ }^{4}$ It is well-known that price and quantity competition yield the same outcome in monopolistic competition models with a continuum of firms (Vives, 1999, p.168).

${ }^{5}$ In the light of this interpretation, one can check that the price equilibrium in the CES model is equivalent to a dominant strategy Nash equilibrium (Behrens and Murata, 2005).
} 
and firms earn zero profits (in which case $E_{r}=w_{r}$ and $E_{s}=w_{s}$ ). More formally, an equilibrium is a solution to the following three conditions:

$$
\begin{aligned}
\int_{\Omega_{r}}\left[c Q_{r}(i)+F\right] \mathrm{d} i & =L_{r}, \\
\int_{\Omega_{s}}\left[c Q_{s}(j)+F\right] \mathrm{d} j & =L_{s}, \\
L_{s} \int_{\Omega_{r}} p_{r}^{*}(i) q_{r s}(i) \mathrm{d} i & =L_{r} \int_{\Omega_{s}} p_{s}^{*}(j) q_{s r}(j) \mathrm{d} j,
\end{aligned}
$$

where all quantities are evaluated at a price equilibrium. We close the model by choosing $w_{r}$ as the numéraire. ${ }^{6}$ Given a price equilibrium, an equilibrium can be determined by solving the three equations (8)-(10) for the three unknowns $n_{r}, n_{s}$ and $w_{s}$.

\section{Autarky}

Assuming that the two countries cannot trade initially with each other, we first characterize the equilibrium and optimum outcomes in the closed economy. Without loss of generality, we consider country $r$ in what follows.

\subsection{Equilibrium}

Inserting (2)-(4) into (6), and letting $q_{r s}(i)=\partial q_{r s}(i) / \partial p_{r}(i)=0$ and $q_{s r}(j)=$ $\partial q_{s r}(j) / \partial p_{s}(j)=0$, Behrens and Murata (2005) have shown that the unique price equilibrium is symmetric and given as follows:

$$
p_{r}^{a}=\left(c+\frac{\alpha}{n_{r}^{a}}\right) w_{r}^{a},
$$

where an $a$-superscript henceforth denotes autarky values.

Given the symmetry of the price equilibrium, the profit of each firm is as follows:

$$
\Pi_{r}^{a}=L_{r} q_{r}^{a}\left(p_{r}^{a}-c w_{r}^{a}\right)-F w_{r}^{a} .
$$

Using the consumer's budget constraint $w_{r}^{a}=n_{r}^{a} p_{r}^{a} q_{r}^{a}$, this can be rewritten as

$$
\Pi_{r}^{a}=p_{r}^{a} q_{r}^{a}\left[L_{r}\left(1-c n_{r}^{a} q_{r}^{a}\right)-F n_{r}^{a}\right] .
$$

\footnotetext{
${ }^{6}$ It can be readily verified that the choice of the numéraire is immaterial in our monopolistic competition framework. This is an important departure from oligopoly models, where the choice of the numéraire is usually not neutral (Gabszewicz and Vial, 1972).
} 
Zero profits then imply that the quantities must be such that

$$
q_{r}^{a}=\frac{1}{c}\left[\frac{1}{n_{r}^{a}}-\frac{F}{L_{r}}\right],
$$

which are positive because $n_{r}^{a} F<L_{r}$ must hold from the resource constraint when $n_{r}^{a}$ firms operate. Utility is then given by

$$
U\left(n_{r}^{a}\right)=n_{r}^{a}\left[1-\mathrm{e}^{-\frac{\alpha}{c}\left(\frac{1}{n_{r}^{a}}-\frac{F}{L_{r}}\right)}\right] .
$$

Note that (12) and (13) hold whenever prices are symmetric and firms earn zero profit. This property will prove to be useful when we subsequently compare the equilibrium and the constrained optimum.

Inserting $q_{r}^{a}=w_{r}^{a} /\left(n_{r}^{a} p_{r}^{a}\right)$ into the labor market clearing condition (8), we get:

$$
n_{r}^{a}=\frac{L_{r}}{F}\left(1-c \frac{w_{r}^{a}}{p_{r}^{a}}\right) .
$$

The equilibrium mass of firms can then be found by using (11) and (14), which yields: ${ }^{7}$

$$
n_{r}^{a}=\frac{\sqrt{4 \alpha c F L_{r}+(\alpha F)^{2}}-\alpha F}{2 c F}>0 .
$$

Finally, inserting (15) into (13), the indirect utility in autarky is given by

$$
U^{a}=\frac{\sqrt{4 \alpha c F L_{r}+(\alpha F)^{2}}-\alpha F}{2 c F}\left[1-\mathrm{e}^{-\frac{2 \alpha F}{\sqrt{4 \alpha c F L_{r}+(\alpha F)^{2}}+\alpha F}}\right],
$$

which is a strictly increasing and strictly concave function of the population size $L_{r}$ for all admissible parameter values.

\subsection{Constrained optimum}

We now ask what the socially optimal mass of varieties is in autarky. Following Dixit and Stiglitz (1977), we focus on a constrained optimum in which the planner chooses prices, quantities, and the mass of varieties such that: (i) utility is maximized; (ii) product and factor markets clear; and (iii) firms make non-negative profits. ${ }^{8}$ Focusing on the symmetric case, the planner chooses $n_{r}^{o}, p_{r}^{o}$ and $q_{r}^{o}$, where an $o^{-}$ superscript henceforth denotes the constrained optimal values. Recalling that (13) holds whenever prices are symmetric and firms earn zero profit, the planner chooses $n_{r}^{o}$ to maximize:

$$
U_{r}^{o}\left(n_{r}^{o}\right)=n_{r}^{o}\left[1-\mathrm{e}^{-\frac{\alpha}{c}\left(\frac{1}{n_{r}^{o}}-\frac{F}{L_{r}}\right)}\right] .
$$

\footnotetext{
${ }^{7}$ Note that the other root is negative and must, therefore, be ruled out.

${ }^{8}$ It can be verified that the unconstrained and constrained optimum yield the same results in our model (see Appendix B for futher details).
} 
Standard calculations show that

$$
\frac{\partial U_{r}^{o}}{\partial n_{r}^{o}}=1-\left(1+\frac{\alpha}{c n_{r}^{o}}\right) \mathrm{e}^{-\frac{\alpha}{c}\left(\frac{1}{n_{r}^{o}}-\frac{F}{L_{r}}\right)}
$$

and

$$
\frac{\partial^{2} U_{r}^{o}}{\partial\left(n_{r}^{o}\right)^{2}}=-\frac{\alpha^{2}}{c^{2}\left(n_{r}^{o}\right)^{3}} \mathrm{e}^{-\frac{\alpha}{c}\left(\frac{1}{n_{r}^{o}}-\frac{F}{L_{r}}\right)}<0,
$$

i.e., $U_{r}^{o}$ is a strictly concave function of $n_{r}^{o}$. Equating (18) to zero, utility maximization requires us to solve the first-order condition

$$
\frac{c n_{r}^{o}}{\alpha+c n_{r}^{o}}=\mathrm{e}^{-\frac{\alpha}{c}\left(\frac{1}{n_{r}^{o}}-\frac{F}{L_{r}}\right)} .
$$

Using (19) we can show the following result:

Proposition 1 (excess entry) There is a unique optimal mass of firms $n_{r}^{o}$ such that $n_{r}^{a}>n_{r}^{o}$. Hence, in equilibrium under autarky, there are too many firms operating at an inefficiently small scale.

Proof. See Appendix C.

Interestingly, this result contrasts starkly with the constant elasticity case, where the equilibrium mass of varieties is also constrained optimal. ${ }^{9}$ Stated differently, the basic CES model does not account for the tendency that too many firms produce at inefficiently small scale in a closed economy (the so-called 'Eastman-Stykolt hypothesis'; Eastman and Stykolt, 1967), an argument often used to criticize importsubstituting industrialization policies (Krugman and Obstfeld, 1997, pp.259-260) or tariff barriers (Horstman and Markusen, 1986) on efficiency grounds. We come back to this point in Section 4.3.

\section{Free trade}

We now analyze the impacts of free trade on welfare and efficiency in a world with variable mark-ups. Section 4.1 analyzes the equilibrium. Section 4.2 then shows the existence of gains from trade and decomposes these gains into product diversity and pro-competitive effects. Section 4.3 finally proves that trade increases efficiency by moving the equilibrium closer to the constrained optimum.

\footnotetext{
${ }^{9}$ This can be seen from Dixit and Stiglitz (1977, p.301), when letting $s \equiv 1$ and $\theta \equiv 0$ in their equations (20) and (21), since we have no numéraire good. Note that the two-factor two-sector CES trade model by Lawrence and Spiller (1983, p.68) even displays insufficient entry. This runs against the general tendency of excess entry obtained under "a range of very plausible situations" (Vives, 1999, p.176).
} 


\subsection{Equilibrium}

Assume that both countries can trade freely. The profits and the first-order conditions are still given by (5) and (6), respectively. We start by showing that free trade leads to product price equalization, which then also implies factor price equalization. ${ }^{10}$

Proposition 2 (price equalization) Free trade leads to both product and factor price equalization for all admissible parameter values.

Proof. Conditions (6) and (7) must hold for both country- $r$ and country- $s$ firms at every price equilibrium which, using (2)-(4), yields

$$
\frac{\partial \Pi_{r}(i)}{\partial p_{r}(i)}-\frac{\partial \Pi_{s}(j)}{\partial p_{s}(j)}=0 \quad \Longleftrightarrow \quad c\left[\frac{w_{r}}{p_{r}(i)}-\frac{w_{s}}{p_{s}(j)}\right]=\ln \left(\frac{p_{r}(i)}{p_{s}(j)}\right) .
$$

It is also readily verified that

$$
Q_{r}(i)-Q_{s}(j) \gtreqless 0 \quad \Longleftrightarrow \quad \frac{-\left(L_{r}+L_{s}\right)}{\alpha} \ln \left(\frac{p_{r}(i)}{p_{s}(j)}\right) \gtreqless 0 .
$$

Furthermore, an equilibrium is such that firms earn zero profit, i.e.,

$$
\begin{aligned}
& \Pi_{r}(i)=w_{r}\left[\left(\frac{p_{r}(i)}{w_{r}}-c\right) Q_{r}(i)-F\right]=0 \\
& \Pi_{s}(j)=w_{s}\left[\left(\frac{p_{s}(j)}{w_{s}}-c\right) Q_{s}(j)-F\right]=0 .
\end{aligned}
$$

Assume that there exists $i \in \Omega_{r}$ and $j \in \Omega_{s}$ such that $p_{r}(i)>p_{s}(j)$. Then condition (20) implies that

$$
\frac{w_{r}}{p_{r}(i)}>\frac{w_{s}}{p_{s}(j)} \quad \Longrightarrow \quad \frac{p_{r}(i)}{w_{r}}<\frac{p_{s}(j)}{w_{s}}
$$

whereas condition (21) implies that $Q_{r}(i)<Q_{s}(j)$. Hence, $\Pi_{r}(i)<\Pi_{s}(j)$, which is incompatible with an equilibrium. We may hence conclude that $p_{r}(i)=p_{s}(j)$ must hold for all $i \in \Omega_{r}$ and $j \in \Omega_{s}$, which shows that product prices are equalized. Condition (20) then shows that $w_{r}=w_{s}$, i.e., factor prices are equalized whenever product prices are equalized, which proves our claim.

\footnotetext{
${ }^{10}$ Note that there is a priori no reason for product price equalization to hold in our setting, even under free trade. This is because firms sell differentiated varieties, factor markets are segmented, and firms are imperfectly competitive. Most studies assume, rather than prove, that product price equalization must hold under free trade in the first place (e.g., Helpman, 1981).
} 
From Proposition 2, we know that $p_{r}=p_{s}=p$ and $w_{r}=w_{s}=w$, which allows us to rewrite (2)-(4) as follows:

$$
q_{r r}=q_{s r}=q_{s s}=q_{r s}=\frac{w}{\left(n_{r}+n_{s}\right) p}
$$

and

$$
\frac{\partial q_{r r}}{\partial p_{r}}=\frac{\partial q_{s r}}{\partial p_{s}}=\frac{\partial q_{s s}}{\partial p_{s}}=\frac{\partial q_{r s}}{\partial p_{r}}=-\frac{1}{\alpha p} .
$$

Inserting (22) and (23) into the first order condition (6), we obtain the price equilibrium:

$$
p^{*}=w\left(c+\frac{\alpha}{n_{r}+n_{s}}\right),
$$

which is a straightforward extension of the autarky case (11). Expression (24) concisely illustrates the pro-competitive effects of international trade. Indeed, once trade occurs, the price-cost margins in both countries decrease. This is an important departure from the CES model, in which such an effect does not arise. Note also that Proposition 2 holds regardless of country size. In autarky, a smaller country tends to have a smaller mass of firms, which implies a higher price-wage ratio. Therefore, the price-wage ratio in a small country decreases more than that in a large country under free trade, i.e., we observe convergence in price-wage ratios across countries. ${ }^{11}$

Since prices and wages are equalized, all firms sell the same quantity $Q=\left(L_{r}+\right.$ $\left.L_{s}\right) q$. Labor market clearing then implies that $n_{r} / n_{s}=L_{r} / L_{s}$, which yields

$$
n_{r}=\frac{L_{r}}{F}\left(1-c \frac{w}{p^{*}}\right) .
$$

Comparing expressions (25) and (14), we see that $n_{r}<n_{r}^{a}$ if and only if the free trade price-wage ratio is smaller than the autarky price-wage ratio. We now show that this is indeed the case.

Proposition 3 (trade and product diversity) When compared with autarky, the mass of varieties produced in each country decreases under free trade, whereas the mass of varieties consumed in each country increases.

Proof. Plugging (24) into (25) and the analogous expression for country $s$, we obtain two equations in the two unknowns $n_{r}$ and $n_{s}$. Solving for the equilibrium masses of firms, we get

$$
n_{r}^{*}=\frac{L_{r}}{L_{r}+L_{s}} \frac{\sqrt{4 \alpha c F\left(L_{r}+L_{s}\right)+(\alpha F)^{2}}-\alpha F}{2 c F}
$$

\footnotetext{
${ }^{11}$ In the two-sector two-factor model of Lawrence and Spiller (1983, Proposition 5), the price of the monopolistically competitive good falls in one country and rises in the other due to changes in relative factor prices. Yet, the price-cost margins remain constant because of the CES assumption.
} 
and

$$
n_{s}^{*}=\frac{L_{s}}{L_{r}+L_{s}} \frac{\sqrt{4 \alpha c F\left(L_{r}+L_{s}\right)+(\alpha F)^{2}}-\alpha F}{2 c F} .
$$

Thus, the equilibrium mass of firms in the global economy is given by

$$
n^{*} \equiv n_{r}^{*}+n_{s}^{*}=\frac{\sqrt{4 \alpha c F\left(L_{r}+L_{s}\right)+(\alpha F)^{2}}-\alpha F}{2 c F},
$$

which is a straightforward extension of the autarky expression (15). This immediately shows that $n^{*}>n_{r}^{a}$ and $n^{*}>n_{s}^{a}$, i.e. the mass of varieties consumed in each country increases. Comparing expressions (11) and (24) then shows that the price-wage ratio in each country decreases. By (14) and (25), this implies that there is exit of firms in each country, i.e. $n_{r}^{*}<n_{r}^{a}$ and $n_{s}^{*}<n_{s}^{a}$.

Proposition 3 illustrates exit of firms due to pro-competitive effects. Indeed, free trade reduces the price-cost margins in both countries, which drives some firms out of each national market (Krugman, 1979; Feenstra, 2003). ${ }^{12}$ Factor market clearing then makes sure that firm-level and total production expands, as labor is reallocated from the (unproductive) fixed requirements of closing firms to the (productive) marginal requirements of surviving firms.

Note, finally, that although there is a growing literature on firm heterogeneity and exit in international trade (e.g., Melitz, 2003), the price-cost margin for each firm is usually assumed to be constant in these models because of the CES specification. ${ }^{13}$ By contrast, our model captures the 'old idea' that international trade in the presence of imperfect competition leads to decreasing mark-up rates and hence to exit of firms even without heterogeneity (Dixit and Norman, 1980).

\subsection{Welfare decomposition and gains from trade}

We now discuss gains from trade. To do so, we use a similar approach to Krugman (1981) and decompose the utility into its basic components. By definition, and because varieties are symmetric under both free trade and autarky, the utility difference can be expressed as follows:

$$
U_{r}^{*}-U_{r}^{a}=n^{*}\left(1-\mathrm{e}^{-\frac{\alpha w^{*}}{n^{*} p^{*}}}\right)-n_{r}^{a}\left(1-\mathrm{e}^{-\frac{\alpha w_{r}^{a}}{n_{r}^{a} p_{r}^{a}}}\right) .
$$

\footnotetext{
${ }^{12}$ In the model of Lawrence and Spiller (1983, Proposition 7), international trade simply leads to a redistribution of existing firms between the two countries while the total mass of firms remains unchanged. This result is driven by changes in relative factor prices under free trade and, as pointed out by the authors, need not hold under variable mark-ups.

${ }^{13}$ One notable exception is the work by Ottaviano and Melitz (2005) who recently proposed a model that explains trade-induced exit by combining pro-competitive effects and firm heterogeneity in a quasi-linear framework.
} 
Adding and subtracting $n_{r}^{a} \mathrm{e}^{-\frac{\alpha w^{*}}{n_{r}^{a} p^{*}}}$, and rearranging the resulting terms, we obtain the following decomposition:

$$
U_{r}^{*}-U_{r}^{a}=\underbrace{n^{*}\left(1-\mathrm{e}^{-\frac{\alpha w^{*}}{n^{*} p^{*}}}\right)-n_{r}^{a}\left(1-\mathrm{e}^{-\frac{\alpha w^{*}}{n_{r}^{a} p^{*}}}\right)}_{\text {Product diversity }}+\underbrace{n_{r}^{a}\left(\mathrm{e}^{-\frac{\alpha w_{r}^{a}}{n_{r}^{a} p_{r}^{a}}}-\mathrm{e}^{-\frac{\alpha w^{*}}{n_{r}^{a} p^{*}}}\right)}_{\text {Pro-competitive effects }},
$$

which isolates the two channels, namely product diversity and pro-competitive effects, through which gains from trade materialize.

We now examine the role and the sign of each component in expression (27) in more details, both from a theoretical and an empirical point of view.

Product diversity: As shown in Proposition 3, free trade expands consumers' choice set in our model, as it does in the CES case, despite the exit of some national producers. Ceteris paribus this raises utility in this model via 'love-of-variety'. This can be seen as follows. Given the wage-price ratio under free trade, $w^{*} / p^{*}$, we have

$$
U_{r}=n\left(1-\mathrm{e}^{-\frac{\alpha w^{*}}{n p^{*}}}\right), \quad \frac{\partial U_{r}}{\partial n}=1-\mathrm{e}^{-\frac{\alpha w^{*}}{n p^{*}}}\left(1+\frac{\alpha w^{*}}{n p^{*}}\right)>0 \quad \forall n .
$$

To obtain the last inequality, let $z \equiv \alpha w^{*} / n p^{*}$ and $h(z) \equiv 1-e^{-z}(1+z)$. Clearly, $h(0)=0$ and $h^{\prime}(z)>0$ for all $z>0$, which shows that for any given 'real wage' $w^{*} / p^{*}$, utility increases with the range of varieties consumed.

Despite its central theoretical role in new trade theory, little is known until now about the empirical importance of gains from product diversity (Feenstra, 1995). Using extremely disaggregated data, Broda and Weinstein (2005) document that the number of product varieties in US imports rose by $251 \%$ between 1972 and 2001, and according to their estimates this maps into US welfare gains of about $2.8 \%$ of GDP. These findings suggest that gains from product diversity may be an important real-world aspect of international trade.

Pro-competitive effects: The second term in (27) captures the beneficial effects of increased price competition in the product market, driving prices closer to marginal costs. This can be seen by comparing expressions (11) and (24). Note that $w_{r}^{a} / p_{r}^{a}=$ $w_{r}^{*} / p_{r}^{*}$ would hold in the constant elasticity case, i.e., there would be no gains from trade due to pro-competitive effects.

It is well-known from various industrial organization studies that prices in many imperfectly competitive industries are increasing functions of producer concentration (see Schmalensee, 1989, pp.987-988, for a survey). In our symmetric equilibria, the Herfindahl-index of concentration, equal to the sum of squared market shares, 
reduces to $H=n(1 / n)^{2}=1 / n$. Hence, by increasing $n$ trade decreases concentration, which in turn maps into lower consumer prices. Several case studies in international trade confirm this 'imports-as-market-discipline hypothesis', i.e. import competition, by increasing the number of competitors in each market, decreases concentration and reduces prices (e.g., Levinsohn, 1993; Harrison, 1994).

Let us summarize our results as follows:

Proposition 4 (gains from trade) Free trade has a positive effect on welfare by both expanding consumers' choice sets ('product diversity') and by driving prices closer to marginal costs ('pro-competitive effects').

Proof. To prove our claim, it is sufficient to discuss the sign of the two components in expression (27). As shown in the above, they are both positive, which ensures gains from trade.

\subsection{Constrained optimum and efficiency}

Since in our model free trade amounts to increasing the population size when compared to autarky, the result on excess entry established in Section 3.2 continues to hold, even under free trade. Stated differently, there is again a unique optimal mass of firms $n^{o}$ such that $n^{*}>n^{o}$. Hence, there are too many firms operating at an inefficiently small scale and the market outcome is not constrained efficient.

It can be readily verified from expression (16) that there are gains from free trade or from an exogenous increase in population, i.e., $\mathrm{d} U^{*} / \mathrm{d} L>0$. Yet, the utility that can be achieved at the constrained optimum also rises due to free trade or to an increase in population. To see this, apply the implicit function theorem to (19), which yields

$$
\frac{\mathrm{d} n^{o}}{\mathrm{~d} L}=\frac{F\left(n^{o}\right)^{2}\left(c n^{o}+\alpha\right)}{L^{2} \alpha}>0
$$

i.e., the optimal mass of firms increases in the population size $L$. Plugging (19) into (17), the optimal utility satisfies $U^{o}=\alpha n^{o} /\left(\alpha+c n^{o}\right)$, which shows that

$$
\frac{\mathrm{d} U^{o}}{\mathrm{~d} L}=\left(\frac{\alpha}{\alpha+c n^{o}}\right)^{2} \frac{\mathrm{d} n^{o}}{\mathrm{~d} L}>0 .
$$

Given that both the equilibrium and the optimum utility increase in $L$, it is a priori unclear whether free trade leads the economy closer to the constrained optimum. We therefore ask whether or not free trade is efficiency enhancing. ${ }^{14}$ We now show

\footnotetext{
${ }^{14}$ Note that there are three different distortions in the model: (i) pricing above marginal cost; (ii) too small quantities produced; and (iii) excess supply of differentiated varieties. We know from second-best theory that correcting one or two of these distortions (e.g., prices closer to marginal costs and larger quantities) is not enough to be even potentially beneficial for the economy.
} 
that free trade is indeed efficiency enhancing, i.e.,

$$
\frac{U^{a}}{\left(U^{a}\right)^{o}}<\frac{U^{*}}{\left(U^{*}\right)^{o}}<1 .
$$

To establish this result, we evaluate (13) at $n^{*}$ and at $n^{o}$. By definition of the optimum $n^{o}$, it must be that $U\left(n^{*}\right)-U\left(n^{o}\right) \leq 0$. We now show that this difference is an increasing function of $L$ and that it converges to zero as $L$ gets arbitrarily large.

Proposition 5 (constrained efficiency) Free trade (or, equivalently, an exogenous increase in population) raises efficiency by monotonically narrowing the gap between the equilibrium utility and the constrained optimal utility. When the population gets arbitrarily large, we have

$$
\lim _{L \rightarrow \infty} U^{*}\left(n^{*}(L)\right)=\lim _{L \rightarrow \infty} U^{o}\left(n^{o}(L)\right)=\frac{\alpha}{c}
$$

Proof. See Appendix D.

Three remarks are in order. First, the market outcome remains inefficient for all (finite) population sizes, and the inefficiency due to excess entry actually increases. Stated differently, free trade does not alleviate the variety problem, even if free trade increases efficiency via pro-competitive effects. Second, when the population gets arbitrarily large $(L \rightarrow \infty)$, the economy converges to the competitive outcome. Because our model has a competitive limit (in the sense that prices converge to marginal costs, as can be seen from expressions (11) and (24)), we fall back on a market outcome that must be efficient. This property also highlights the fact that free trade between large countries is more efficiency enhancing than free trade between small countries (see also Lawrence and Spiller, 1983, Proposition 10). Last, the maximal utility that can be achieved in the limit is determined solely by tastes and technology.

\section{Conclusions}

We have developed a simple monopolistic competition model that allows us to concisely highlight the gains from trade due to product diversity and pro-competitive effects. We have shown that, as in the CES model, trade expands consumers' choice sets which, ceteris paribus, makes them better off due to 'love-of-variety'. In addition, and contrary to the CES model, trade also drives prices closer to marginal costs via pro-competitive effects, which leads to a reduction of the mass of varieties produced in each country due to exit of firms. Finally, we also showed that free 
trade enhances efficiency by moving the economy closer to the constrained optimum. When the population size gets arbitrarily large, our model has a competitive limit and the market outcome is constrained efficient.

A final word of caution is in order. The model itself may be simply viewed as an analytically solvable example of Krugman (1979). Indeed, Proposition 3 is not original since the result has been around in the literature (see Krugman, 1979; Feenstra, 2003, Ch.4). Yet, due to its tractability, our specification allows us to move beyond Krugman's original contribution in three respects: first, it allows us to concisely analyze the constrained optimum; second, we can decompose gains from trade into those due to product diversity and those due to pro-competitive effects; and third, we can analyze the issue of efficiency in general equilibrium under monopolistic competition.

\section{References}

[1] Behrens, K. and Y. Murata (2005) A functional separability approach to monopolistic competition: the Dixit-Stiglitz model reconsidered, KIER Discussion Paper \#COE21/87, Kyoto University.

[2] Broda, C. and D. Weinstein (2005) Globalization and the gains from variety. NBER Working Paper \#10314.

[3] Dixit, A.K. and J.E. Stiglitz (1977) Monopolistic competition and optimum product diversity, American Economic Review 67, 297-308.

[4] Dixit, A.K. and V. Norman (1980) Theory of International Trade: A Dual General Equilibrium Approach. Cambridge, MA: Cambridge Univ. Press.

[5] Dixit, A.K. (2004) Some reflections on theories and applications of monopolistic competition. In: Brakman, S. and B.J. Heijdra (eds.) The Monopolistic Competition Revolution in Retrospect. Cambridge, MA: Cambridge Univ. Press, pp. 123-133.

[6] Eastman, H. and S. Stykolt (1967) The Tariff and Competition in Canada. Toronto: MacMillan.

[7] Feenstra, R.E. (1995) Estimating the effects of trade policy. In: Grossman, G.E. and K. Rogoff (eds.) Handbook of International Economics, vol. 3. NorthHolland: Elsevier, pp. 1553-1595. 
[8] Feenstra, R.E. (2003) Advanced International Trade: Theory and Evidence. Princeton, NJ: Princeton Univ. Press.

[9] Gabszewicz, J.-J. and J.P. Vial (1972) Oligopoly à la Cournot in general equilibrium analysis, Journal of Economic Theory 4, 381-400.

[10] Harrison, A.E. (1994) Productivity, imperfect competition, and trade reform: theory and evidence, Journal of International Economics 36, 53-74.

[11] Helpman, E. (1981) International trade in the presence of product differentiation, economies of scale, and monopolistic competition, Journal of International Economics 11, 305-340.

[12] Helpman, E. and P.R. Krugman (1985) Market Structure and Foreign Trade. Cambridge, MA: MIT Press.

[13] Horstman, I. and J.R. Markusen (1986) Up the average cost curve: inefficient entry and the new protectionism, Journal of International Economics 20, 225247.

[14] Krugman, P.R. (1979) Increasing returns, monopolistic competition, and international trade, Journal of International Economics 9, 469-479.

[15] Krugman, P.R. (1980) Scale economies, product differentiation and the pattern of trade, American Economic Review 70, 950-959.

[16] Krugman, P.R. (1981) Intraindustry specialization and the gains from trade, Journal of Political Economy 89, 959-973.

[17] Krugman, P.R. and M. Obstfeld (1997) International Economics: Theory and Policy, fourth edition. Reading, MA: Addison Wesley.

[18] Lawrence, C. and P.T. Spiller (1983) Product diversity, economies of scale, and international trade, Quarterly Journal of Economics 98, 63-83.

[19] Levinsohn, J. (1993) Testing the imports-as-market-discipline hypothesis, Journal of International Economics 35, 1-22.

[20] Melitz, M.J. (2003) The impact of trade on intra-industry reallocations and aggregate industry productivity, Econometrica 71, 1695-1725.

[21] Melitz, M.J. and G.I.P. Ottaviano (2005) Market size, trade, and productivity, NBER Working Paper \#11393. 
[22] Neary, P.J. (2004) Monopolistic competition and international trade theory. In: Brackman, S. and B.J. Heijdra (eds.) The Monopolistic Competition Revolution in Retrospect. Cambridge, MA: Cambridge Univ. Press, pp. 159-184.

[23] Schmalensee, R. (1989) Inter-industry studies of structure and performance. In: Schmalensee, R. and R.D. Willig (eds.) Handbook of Industrial Organization, vol.2. North-Holland: Elsevier, pp. 951-1009.

[24] Vives, X. (1999) Oligopoly Pricing: Old Ideas and New Tools. Cambridge, MA: MIT Press.

[25] Wong, K.-Y. (1995) International Trade in Goods and Factor Mobility. Cambridge, MA: MIT Press.

\section{Appendix A: Derivation of the demand functions}

A representative consumer in country $r$ solves problem (1). Letting $\lambda$ stand for the Lagrange multiplier, the first order conditions for an interior solution are given by:

$$
\begin{aligned}
\alpha \mathrm{e}^{-\alpha q_{r r}(j)}-\lambda p_{r}(j)=0, & \forall j \in \Omega_{r} \\
\alpha \mathrm{e}^{-\alpha q_{s r}(k)}-\lambda p_{s}(k)=0, & \forall k \in \Omega_{s}
\end{aligned}
$$

and the budget constraint

$$
\int_{\Omega_{r}} p_{r}(j) q_{r r}(j) \mathrm{d} j+\int_{\Omega_{s}} p_{s}(k) q_{s r}(k) \mathrm{d} k-E_{r}=0 .
$$

Taking the ratio of (28) with respect to $i$ and $j$, we obtain

$$
\mathrm{e}^{-\alpha\left[q_{r r}(j)-q_{r r}(i)\right]}=\frac{p_{r}(j)}{p_{r}(i)} \quad \Longrightarrow \quad q_{r r}(j)=q_{r r}(i)+\frac{1}{\alpha} \ln \left[\frac{p_{r}(i)}{p_{r}(j)}\right] \quad \forall j, i \in \Omega_{r}
$$

Multiplying the last expression by $p_{r}(i)$ and integrating with respect to $i \in \Omega_{r}$ we obtain:

$$
q_{r r}(j) \int_{\Omega_{r}} p_{r}(i) \mathrm{d} i=\int_{\Omega_{r}} p_{r}(i) q_{r r}(i) \mathrm{d} i+\frac{1}{\alpha} \int_{\Omega_{r}} \ln \left[\frac{p_{r}(i)}{p_{r}(j)}\right] p_{r}(i) \mathrm{d} i .
$$

Analogously, taking the ratio of (28) and (29) with respect to $i$ and $j$, we get:

$$
\mathrm{e}^{-\alpha\left[q_{r r}(j)-q_{s r}(i)\right]}=\frac{p_{r}(j)}{p_{s}(i)} \Longrightarrow q_{r r}(j)=q_{s r}(i)+\frac{1}{\alpha} \ln \left[\frac{p_{s}(i)}{p_{r}(j)}\right] \quad \forall j \in \Omega_{r}, \forall i \in \Omega_{s} .
$$

Multiplying the last expression by $p_{s}(i)$ and integrating with respect to $i \in \Omega_{s}$ we obtain:

$$
q_{r r}(j) \int_{\Omega_{s}} p_{s}(i) \mathrm{d} i=\int_{\Omega_{s}} p_{s}(i) q_{s r}(i) \mathrm{d} i+\frac{1}{\alpha} \int_{\Omega_{s}} \ln \left[\frac{p_{s}(i)}{p_{r}(j)}\right] p_{s}(i) \mathrm{d} i .
$$


Summing (31) and (32), and using the budget constraint (30), we finally obtain the demands (2). The derivations of the demands (3) are analogous.

\section{Appendix B: Unconstrained optimum}

Denote by a $u$-superscript the unconstrained optimal values. In the unconstrained optimum, the planner can use lump-sum transfers to compensate firms for the losses they make under marginal cost pricing. Marginal cost pricing is such that $p_{r}^{u}=c w_{r}$, which implies that firms' profit is then given by $\Pi=-F w_{r}<0$. Hence, when there is a mass of $n_{r}^{u}$ firms operating, a lump-sum tax of $\left(F w_{r} n_{r}^{u}\right) / L_{r}$ is levied on each consumer's income in country $r$. The income net of this tax is then given by

$$
E_{r}=w_{r}\left(1-\frac{F n_{r}^{u}}{L_{r}}\right),
$$

which is positive since $F n_{r}^{u}<L_{r}$ must hold from the labor market resource constraint. In the symmetric case, $q_{r}=E_{r} /\left(n_{r}^{u} p_{r}^{u}\right)$. Using (33) and $p_{r}^{u}=c w_{r}$, we get

$$
q_{r}=\frac{w_{r}}{p_{r}^{u}}\left(\frac{1}{n_{r}^{u}}-\frac{F}{L_{r}}\right)=\frac{1}{c}\left(\frac{1}{n_{r}^{u}}-\frac{F}{L_{r}}\right) .
$$

It is redily verified that we have labor market clearing. Plugging (34) into the utility function, we get

$$
U_{r}^{u}\left(n_{r}^{u}\right)=n_{r}^{u}\left[1-\mathrm{e}^{-\frac{\alpha}{c}\left(\frac{1}{n_{r}^{u}}-\frac{F}{L_{r}}\right)}\right],
$$

which is identical to the corresponding expression in the constrained optimum. Hence, $n_{r}^{u}=n_{r}^{o}$ and the unconstrained and the constrained optimum yield the same outcome.

\section{Appendix C: Proof of Proposition 1}

We need to solve the condition

$$
f\left(n_{r}^{o}\right)=g\left(n_{r}^{o}\right), \quad \text { where } \quad f\left(n_{r}^{o}\right) \equiv \frac{c n_{r}^{o}}{\alpha+c n_{r}^{o}} \quad \text { and } \quad g\left(n_{r}^{o}\right) \equiv \mathrm{e}^{-\frac{\alpha}{c}\left(\frac{1}{n_{r}^{o}}-\frac{F}{L_{r}}\right)}
$$

for $n_{r}^{o}$ and compare its solution to the market outcome $n_{r}^{a}$. Note first that $f$ is strictly increasing in $n_{r}^{o}$, taking values from 0 to 1 , and that $g$ is also strictly increasing, taking values from 0 to $\exp \left[\alpha F /\left(c L_{r}\right)\right]>1$. Some standard calculations show that there is a unique intersection since: (i) both functions are continuous; (ii) $f$ is concave, whereas $g$ is convex for $n_{r}^{o}$ sufficiently small; (iii) the slope of $f$ is strictly 
greater than that of $g$ for $n_{r}^{o}$ sufficiently small; ${ }^{15}$ and (iv) $g$ admits a single value for which its second order derivative is equal to zero.

We next show that $n_{r}^{a}>n_{r}^{o}$. To prove our claim, we use a convexity argument. The equilibrium mass of varieties is given by (15), whereas the optimal mass of varieties is the unique solution to (35). First, evaluate $f\left(n_{r}^{a}\right)$, which yields

$$
f\left(n_{r}^{a}\right)=\frac{c n_{r}^{a}}{\alpha+c n_{r}^{a}}=\frac{-\alpha F+\sqrt{\alpha F\left(4 c L_{r}+\alpha F\right)}}{\alpha F+\sqrt{\alpha F\left(4 c L_{r}+\alpha F\right)}}=\frac{-2 \alpha F+X_{r}}{X_{r}}
$$

where $X_{r} \equiv \alpha F+\sqrt{\alpha F\left(4 c L_{r}+\alpha F\right)}$. Second, evaluate $g\left(n_{r}^{a}\right)$ to get

$$
g\left(n_{r}^{a}\right)=\mathrm{e}^{-\frac{\alpha}{c}\left(\frac{1}{n_{r}^{a}}-\frac{F}{L_{r}}\right)}=\mathrm{e}^{-\frac{2 \alpha F}{X_{r}}} .
$$

Let $Y_{r} \equiv(2 \alpha F) / X_{r}$ and $f\left(Y_{r}\right)=\mathrm{e}^{-Y_{r}}$. Note that (36) can then be expressed as $1-Y_{r}$, which is the tangent to (37) evaluated at $Y_{r}=0$ :

$$
1-Y_{r}=f(0)+f^{\prime}(0)\left(Y_{r}-0\right)
$$

Since (37) is strictly convex, it lies strictly above its tangent. Put differently, $1-Y_{r}<$ $\mathrm{e}^{-Y_{r}}$ holds for every $Y_{r}>0$. Hence, the right-hand side exceeds the left-hand side at the equilibrium mass of firms $n_{r}^{a}$. By uniqueness of the optimal mass of firms, and since the right-hand side of (35) exceeds the left-hand side for sufficiently large values of $n_{a}^{r}$, we may conclude that $n_{r}^{a}>n_{r}^{o}$, which proves our claim.

\section{Appendix D: Proof of Proposition 5}

Recalling that (13) holds whenever prices are symmetric and firms earn zero profit, the value of $n^{o}$ is by definition the unique solution to the first-order condition (19). To see that the economy converges to the constrained optimum as $L$ increases, note that by stricty concavity of $U$ in $n$ the condition

$$
U\left(n^{o}\right)<U\left(n^{*}\right)+\frac{\partial U}{\partial n}\left(n^{*}\right)\left(n^{o}-n^{*}\right)
$$

holds. Since, by definition, $U\left(n^{o}\right)>U\left(n^{*}\right)$ and since $n^{*}>n^{o}$ because there is excess entry, we have

$$
\frac{\partial U}{\partial n}\left(n^{*}\right)<\frac{U\left(n^{o}\right)-U\left(n^{*}\right)}{n^{o}-n^{*}}<0
$$

${ }^{15}$ More formally, one can show that

$$
\lim _{n_{r}^{o} \rightarrow 0}\left(\frac{c n_{r}^{o}}{\alpha+c n_{r}^{o}}\right)^{\prime}=\frac{c}{\alpha}>\lim _{n_{r}^{o} \rightarrow 0}\left(\mathrm{e}^{-\frac{\alpha}{c}\left(\frac{1}{n_{r}^{o}}-\frac{F}{L}\right)}\right)^{\prime}=0 .
$$

Since the limit of the right-hand side and the left-hand side are equal to zero for $n_{r}^{o} \rightarrow 0$, we thus have shown by continuity that the right-hand side lies below the left-hand side for $n_{r}^{o}$ small enough. 
Now observe that the derivative of (38) with respect to $L$ is given by

$$
\frac{\partial^{2} U}{\partial n \partial L}\left(n^{*}\right)=\frac{4(\alpha F)^{3}(2 c L+\alpha F-D) e^{-\alpha F\left(\frac{2}{D-\alpha F}-\frac{1}{c L}\right)}}{L D(D-\alpha F)^{3}}>0
$$

where $D \equiv \sqrt{4 \alpha c F L+(\alpha F)^{2}}$. This derivative converges to 0 when $L \rightarrow \infty$. Using condition (38), we may thus conclude that

$$
\lim _{L \rightarrow \infty} \frac{U\left(n^{o}\right)-U\left(n^{*}\right)}{n^{o}-n^{*}}=0 .
$$

Furthermore, it is readily verified that

$$
\frac{U\left(n^{o}\right)-U\left(n^{*}\right)}{n^{o}-n^{*}}=1-\frac{n^{o} \mathrm{e}^{-\frac{\alpha}{c}\left(\frac{1}{n^{o}}-\frac{F}{L}\right)}-n^{*} \mathrm{e}^{-\frac{\alpha}{c}\left(\frac{1}{n^{*}}-\frac{F}{L}\right)}}{n^{o}-n^{*}} .
$$

Since this expression converges to 0 , by (39), the right-hand side must satisfy the following condition:

$$
\begin{array}{ll} 
& \lim _{L \rightarrow \infty} \frac{n^{o} \mathrm{e}^{-\frac{\alpha}{c}\left(\frac{1}{n^{o}}-\frac{F}{L}\right)}-n^{*} \mathrm{e}^{-\frac{\alpha}{c}\left(\frac{1}{n^{*}}-\frac{F}{L}\right)}}{n^{o}-n^{*}}=1 \\
\Longleftrightarrow \quad \lim _{L \rightarrow \infty}\left(n^{o} \mathrm{e}^{-\frac{\alpha}{c}\left(\frac{1}{n^{o}}-\frac{F}{L}\right)}-n^{*} \mathrm{e}^{-\frac{\alpha}{c}\left(\frac{1}{n^{*}}-\frac{F}{L}\right)}\right)=\lim _{L \rightarrow \infty}\left(n^{o}-n^{*}\right) \\
\Longleftrightarrow \quad \lim _{L \rightarrow \infty} n^{*}\left(1-\mathrm{e}^{-\frac{\alpha}{c}\left(\frac{1}{n^{*}}-\frac{F}{L}\right)}\right)=\lim _{L \rightarrow \infty} n^{o}\left(1-\mathrm{e}^{-\frac{\alpha}{c}\left(\frac{1}{n^{o}}-\frac{F}{L}\right)}\right) \\
\Longleftrightarrow \quad \lim _{L \rightarrow \infty} U\left(n^{o}\right)=\lim _{L \rightarrow \infty} U\left(n^{*}\right) .
\end{array}
$$

This establishes that the equilibrium utility converges to the constrained optimal utility as the population gets arbitrarily large. ${ }^{16}$ The value of $\lim _{L \rightarrow \infty} U\left(n^{o}\right)=\alpha / c$ can then be obtained by noting that $U\left(n^{o}\right)=\alpha n^{o} /\left(\alpha+c n^{o}\right)$ and that $n^{o}$ is strictly increasing in $L$.

Finally, to see that convergence is monotonic, let $X \equiv \alpha F+\sqrt{\alpha F(4 c L+\alpha F)}$ as in Appendix $\mathrm{C}$ and evaluate (19) at $n^{*}$ to obtain the condition

$$
1-\frac{2 \alpha F}{X}-\mathrm{e}^{-\frac{2 \alpha F}{X}}<0,
$$

where the inequality is directly due to the tangency property established in Appendix C. Note that the left-hand side is a monotonically increasing function of $L$, which shows that the difference in slopes between $n^{o}$ and $n^{*}$ decreases with increasing values of $L$. By strict concavity of $U$, this in turn implies that the gap between $U\left(n^{o}\right)$ and $U\left(n^{*}\right)$ decreases monotonically with increasing values of $L$.

\footnotetext{
${ }^{16}$ Note that this does not imply that $\lim _{L \rightarrow \infty}\left(n^{o}-n^{*}\right)=0$. In fact, although both values converge to infinity, their gap actually gets larger. Hence, the problem of excess variety does not get better with larger population sizes, although the equilibrium utility gets closer to the constrained optimal utility since the price-wage ratio decreases faster than the variety gap.
} 